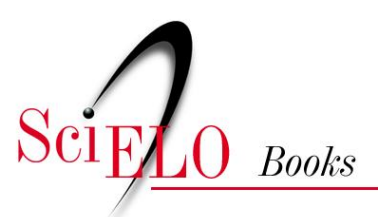

\title{
11. Ecologia dos vetores
}

\author{
Carlos Eduardo Almeida \\ Marli Maria Lima \\ Jane Costa
}

ALMEIDA, CE., LIMA, MM., and COSTA, J. Ecologia dos vetores. In: GALVÃO, C., org. Vetores da doença de chagas no Brasil [online]. Curitiba: Sociedade Brasileira de Zoologia, 2014, pp. 210235. Zoologia: guias e manuais de identificação series. ISBN 978-85-98203-09-6. Available from

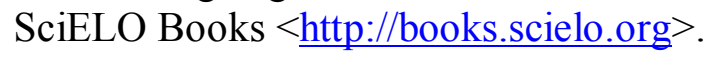

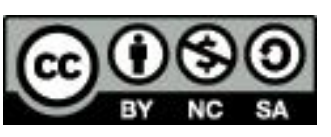

All the contents of this chapter, except where otherwise noted, is licensed under a Creative Commons Attribution-Non Commercial-ShareAlike 3.0 Unported.

Todo o conteúdo deste capítulo, exceto quando houver ressalva, é publicado sob a licença Creative Commons Atribuição Uso Não Comercial - Partilha nos Mesmos Termos 3.0 Não adaptada.

Todo el contenido de este capítulo, excepto donde se indique lo contrario, está bajo licencia de la licencia Creative Commons Reconocimento-NoComercial-CompartirIgual 3.0 Unported. 


\section{Ecologia dos vetores}

\section{(Carlos Eduardo Almeida, Marli Maria Lima \& Jane Costa)}

"Na ansiedade do irrealizado

A angústia da frustração.

Na espera do porvir

O não chegar à solução.

Na decadência física a vir

O sentido último da vida

Da realização, a vaidade

Da mediocridade ambiente, a resistência

Do ideal que se foi, a persistência

Da pureza juvenil, a saudade"

(Oswaldo Paulo Forattini, 1979) ${ }^{1}$

O termo ecologia foi proposto pela primeira vez por Haeckel (1869, apud Acot 1990), como a ciência que estuda os ecossistemas e a interação entre as diferentes espécies de seres vivos, e destes com fatores abióticos (não vivos, como elementos minerais e climáticos). Esta ciência apresenta diversos ramos, como ecologia vegetal, ecologia animal, ecologia da conservação, agroecologia, entre outros. Já a epidemiologia aborda o estudo da determinação causal das doenças para o ser humano. Ambas as ciências demandam uma interação transdisciplinar, apresentando um relativo grau de dependência de outras áreas de estudo, como por exemplo, da geologia, zoologia, botânica, genética, etc. (MacMahon \& Pugh 1975). Surge então, a eco-epidemiologia, que integra as duas ciências (Susser \& Susser 1996).

A ecologia dos vetores da doença de Chagas será apresentada neste capítulo sob um âmbito eco-epidemiológico. Como alguns termos e conceitos utilizados na ecologia dos vetores são pouco usuais na ecologia geral, o seu uso adequado, a sua origem e a aplicabilidade neste campo de estudo também serão aqui discutidos e ilustrados.

\section{Ecossistemas habitados pelos vetores}

Admite-se que os triatomíneos são capazes de habitar todos os ecossistemas equatoriais, tropicais e subtropicais. Em 1980, Oswaldo Paulo Forattini publicou uma obra que se tornou clássica, provendo um estudo de notável riqueza sobre a biogeografia dos triatomíneos no Brasil. Nesta obra, Forattini analisa uma série de fatores eco-epidemiológicos, tais como movimentos migratórios humanos e a dispersão passiva dos triatomíneos, conectando estas observações com informações sobre a vegetação, a geologia, o clima, entre outras. Desta forma, o referido autor efetuou inferências

1 O Professor Foratitini (1924-2007) lecionou na Faculdade de Higiene e Saúde Pública da Universidade de São Paulo, onde, com maestria, obteve êxito no que ele mesmo considerou um desafio: aplicar a Ecologia no campo da Epidemiologia. Naquela ocasião, a Ecologia não apresentava enfoque para a saúde pública e medicina. Assim, o Professor instituiu a disciplina “Ecologia em Saúde Pública", ministrada por ele entre as décadas de 1990 e início da de 2000 (Sallum et al. 2007). 
pertinentes sobre os centros de origem e dispersão de triatomíneos, bem como seus possíveis refúgios naturais. Como um dos exemplos da abrangência dessa obra, podemos citar sua hipótese sobre o centro de origem e dispersão dos membros do complexo Triatoma brasiliensis ${ }^{2}$ na região de Caatinga, acima do Rio São Francisco. 0 centro de origem foi confirmado 24 anos mais tarde, através de modernas técnicas moleculares e abordagens baseadas na filogeografia (Monteiro et al. 2004).

O cenário eco-epidemiológico da doença de Chagas vem sofrendo alterações relevantes: Triatoma infestans foi eliminado em praticamente todo o Brasil (veja capítulo 2) e muitas espécies foram descritas e algumas foram sinonimizadas (veja capítulo 3; Galvão et al. 2003, Costa \& Lorenzo 2009). Assim, reapresenta-se brevemente os quatro principais ecossistemas brasileiros (Figura 11.1) nos quais os triatomíneos são epidemiologicamente importantes. Esses ecossistemas foram detalhadamente discutidos no estudo de Forattini (1980). As adaptações e atualizações são inseridas entre colchetes:

I - A Caatinga [CA, Figura 11.2], incluindo a área de transição do agreste, semi-árido nordestino: região onde T. brasiliensis e T. pseudomaculata são autóctones [Panstrongylus megistus foi introduzido no semiárido, onde colonizou os domicílios. Entretanto, Dias et al. (2000) consideraram a espécie praticamente eliminada neste ecossistema, assim como T. infestans];

II - O Cerrado [CR, Figura 11.3], incluindo as áreas de transição de Maranhão-Piauí, da Bahia, do Pantanal e do Chaco Oriental: A principal espécie sob o ponto de vista epidemiológico é Triatoma sordida;

\footnotetext{
2 na ocasião da publicação do estudo de Forattini (1980) três dos membros do complexo T. brasiliensis encontravam-se
} em sinonímia. Atualmente o complexo T. brasiliensis é composto por T. brasiliensis brasiliensis, T. b. macromelasoma, T. juazeirensis, T. melanica e T. sherlocki (Costa \& Felix 2007, Costa et al. 2003, Mendonça et al. 2009).

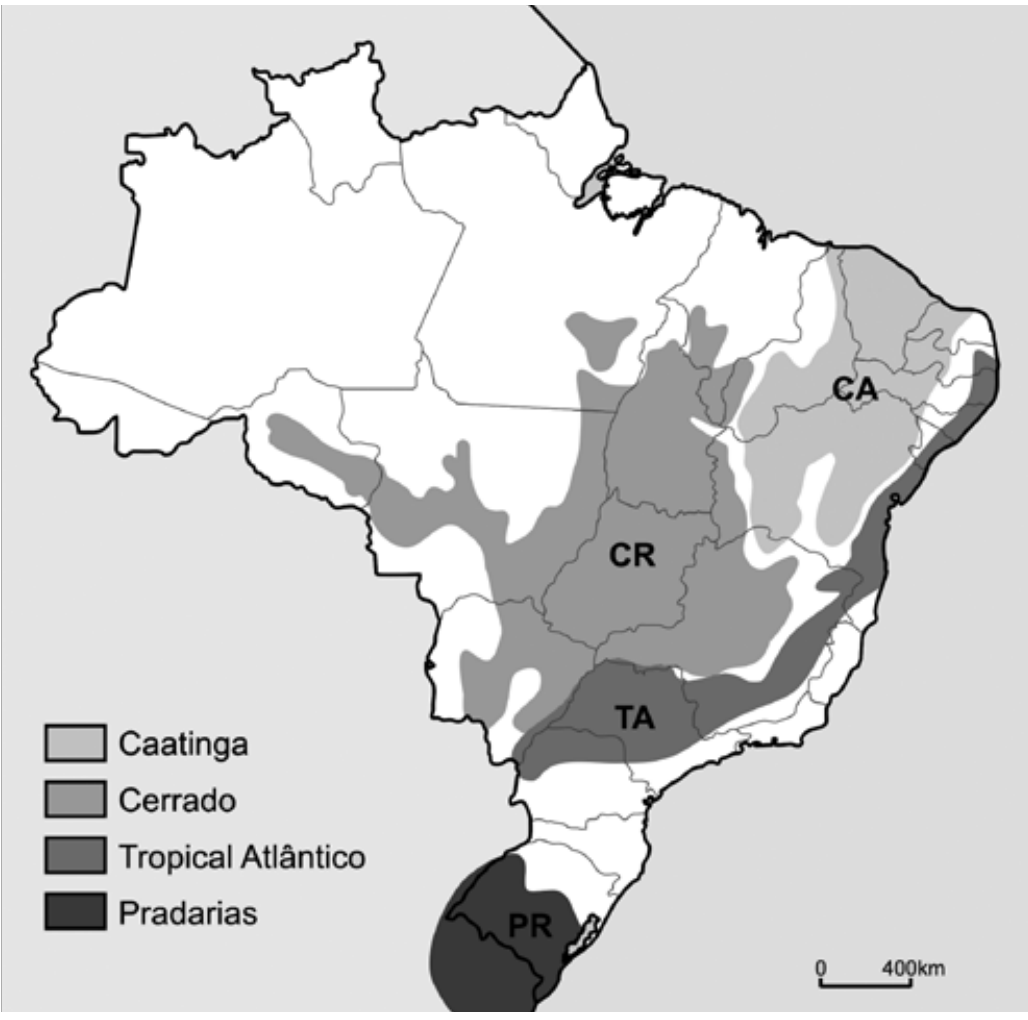

Figura 11.1: Ilustração redesenhada de Forattini (1980), demonstrando os ecossistemas associados às áreas onde a transmissão da doença de Chagas pode ser atribuída aos vetores. CA: Caatinga, CR: Cerrado, TA: Tropical Atlântico, PR: Pradarias.

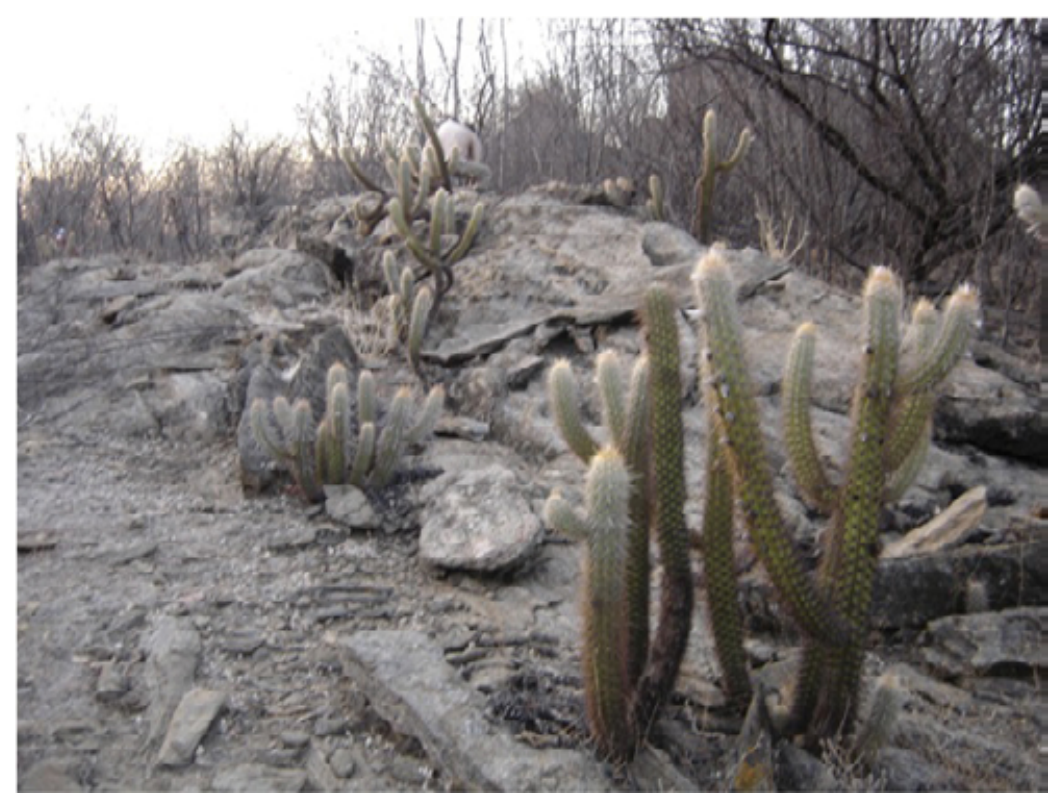

Figura 11.2: O ambiente silvestre na Caatinga na Paraíba, onde exemplares de $T$. brasiliensis foram capturados. 
III - Tropical atlântico [TA, Figura 11.4], subdividido nas áreas setentrional e meridional do Sistema da Serra do Mar, e do planalto paulista, mineiro e paranaense: Panstrongylus megistus é autóctone e o principal vetor [Recentemente, Triatoma vitticeps tem mostrado índices preocupantes de captura domiciliar e foi incriminado pela transmissão da doença de Chagas neste ecossistema no município de São Fidelis, no estado do Rio de Janeiro por Lorosa et al. (2003)];

IV - Pradarias Mistas Subtropicais [PR, Figura 11.5], como parte de domínio que se estende além dos limites brasileiros na região sul do Brasil [T. infestans foi um importante vetor no passado, mas a partir da década de 1990, Triatoma rubrovaria passou a ser o triatomíneo mais capturado nos domicílios no estado do Rio Grande do Sul (Almeida et al. 2000). Salvatella et al. (1995) também relataram quadro semelhante para esta espécie no Uruguai].

\section{Ecótopos dos vetores}

Em 2000, Gaunt \& Miles mencionaram os avanços observados na sistemática dos triatomíneos em contraste com as lacunas que ainda existem no campo da ecologia e biologia. Ainda hoje, poucos estudos foram apresentados, como por exemplo, sobre as flutuações populacionais, mesmo

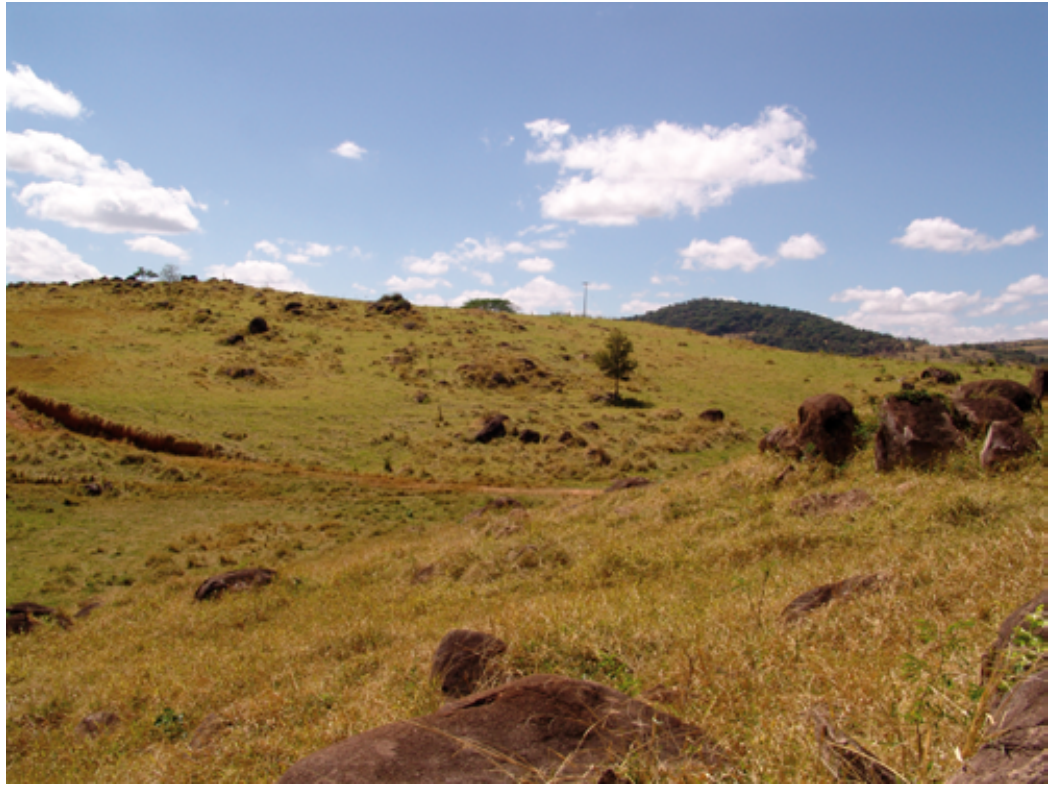

Figura 11.3: O Cerrado no estado de São Paulo, onde $T$. wygodzinskyi foi coletado sobre rochas.

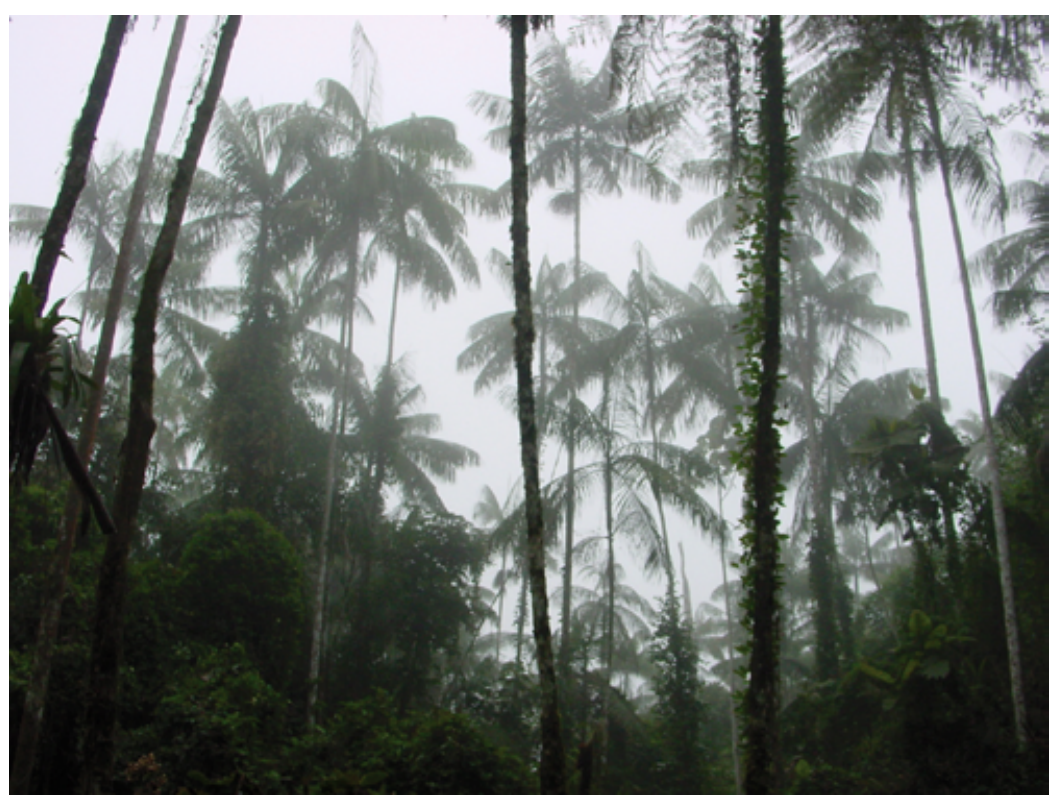

Figura 11.4: A Mata Atlântica Tropical no Parque Nacional do Itatiaia, Rio de Janeiro, onde se tem registro da invasão de $T$. vitticeps nos domicílios.

para os mais importantes vetores autóctones da doença de Chagas no Brasil, como T. brasiliensis (Costa \& Lorenzo 2009).

Antes de tratar dos ecótopos dos triatomíneos é necessário o esclarecimento sobre o termo, para uma utilização apropriada e em consenso. Segundo Klijn \& Haes (1994), de acordo com o conceito de ecossistema, que combina fatores bióticos e abióticos numa mesma unidade, o ecótopo diz respeito a uma estratificação da paisagem do ecossistema em subunidades ecologicamente distintas, também baseadas na combinação de fatores bióticos e abióticos. O ecótopo intradomiciliar, por exemplo, tem o ser humano como um dos elementos dentro dos fatores bióticos e a baixa incisão direta de raios solares como exemplo de fator abiótico. 
O encontro esporádico de um ou poucos espécimes em determinado ecótopo não é suficiente para se afirmar que a espécie apresenta aquele ambiente como o seu ecótopo. O encontro, especialmente de adultos, em um ecótopo pode tratar-se simplesmente de invasão. Assim, para associar uma espécie a um ecótopo é necessário o encontro de espécimes em diferentes estádios de desenvolvimento, coabitando o mesmo ambiente.

Os triatomíneos mais estudados são justamente aqueles associados a ecótopos artificiais, especialmente os domicílios, representando uma pequena parcela do universo de espécies conhecidas (veja capítulos 2, 3 e 8). A grande maioria delas

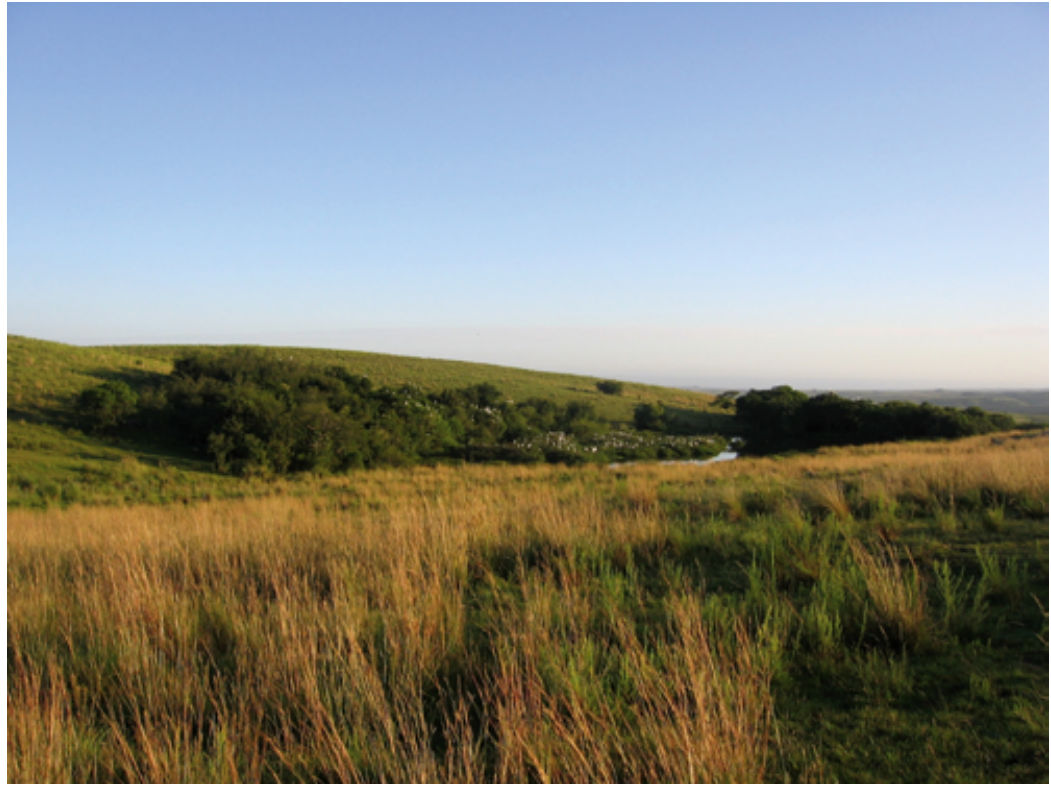

Figura 11.5: O Pampa Gaúcho no Rio Grande do Sul, onde exemplares de $T$. rubrovaria, $T$. circummaculata e T. carcavalloi podem ser coletados em Pradarias Mistas Subtropicais. permanece com sua distribuição restrita a diferentes tipos de ecótopos naturais (ou silvestres).

Para simplificar a definição dos ecótopos naturais dos triatomíneos será realizada uma adaptação da grade proposta por Gaunt \& Miles (2000). Esses autores sugeriram que os ecótopos foram responsáveis pela deriva genética (evolução independente) para grandes linhagens no grupo, dividindo-os primariamente em um ramo de espécies arbóreas e dois ramos terrestres (Tabela 11.1). Os triatomíneos arbóreos ocupam principalmente as palmeiras, ao passo que os terrestres habitam complexos rochosos e buracos no solo construídos ou utilizados por animais, como aqueles sob raízes de árvores robustas. Essa especialização ecotípica foi resultado de uma longa trajetória evolutiva. Nesse contexto, os referidos autores consideram que dentro de um táxon (um gênero, no caso) poucas espécies evoluíram de forma a ocupar um ecótopo não usual para a linhagem ancestral. Contudo, as exceções são observadas para todos os grupos, como será exemplificado a seguir.

Gaunt \& Miles (2000) sugerem que o gênero Rhodnius surgiu a partir de uma linhagem arborícola, associada a diferentes espécies de palmeiras. Conforme Tabela 11.1, $R$. domesticus, entretanto, ocorre em bromélias e ocos de árvores. Lima \& Sarquis (2008) reportaram a ocorrência de $R$.

Tabela 11.1 - Ecótopos silvestres primários associados aos principais grupos de triatomineos.

Adaptação de Gaunt \& Miles (2000)

\begin{tabular}{llll}
\hline Ecótopo silvestre primário & Gênero predominante & Exemplo de exceção \\
\hline Arbóreas & $\begin{array}{l}\text { Especialmente } \\
\text { Palmeiras }\end{array}$ & Espécies do gênero Rhodnius & $\begin{array}{l}\text { Rhodnius domesticus: ocorre em } \\
\text { bromélias e buracos de árvores }\end{array}$ \\
Terrestres & Buracos de animais & $\begin{array}{l}\text { Espécies do gênero } \\
\text { Panstrongylus }\end{array}$ & $\begin{array}{l}\text { Panstrongylus lignarius: ocorre em buracos } \\
\text { de árvores e livre sobre a copa das árvores }\end{array}$ \\
& Complexos rochosos & Espécies do gênero Triatoma & $\begin{array}{l}\text { Triatoma pseudomaculata: ocorre sob } \\
\text { a casca e em buracos de árvores }\end{array}$ \\
\hline
\end{tabular}


nasutus tanto em palmeiras, quanto na oiticica (Licania rigida). Esta última trata-se de uma árvore robusta, não relacionada e tampouco inserida no grupo das palmeiras. Esses autores atribuíram essa associação atípica a um resultado das modificações que o ser humano vem promovendo ao ecossistema.

As espécies do gênero Panstrongylus tem os buracos construídos por animais, como o tatu, ou formados espontaneamente entre as raízes de árvores robustas como ecótopo primário. Entretanto, um dos mais importantes vetores da doença de Chagas no Brasil ( $P$. megistus) ocorre também em ocos de árvores e coroas de palmeiras. Na Amazônia, adultos de $P$. lignarius ocorrem livres sobre os troncos e entre as folhagens das árvores, ao passo que as ninfas se refugiam nos ocos, associadas principalmente com lagartixas do gênero Thecadactylus (Tabela 11.1).

O gênero Triatoma tem como ecótopo primário as formações rochosas. Entretanto, dois dos mais importantes vetores da endemia chagásica no Brasil tem nos vegetais seu principal ecótopo: T. sordida é o triatomíneo mais capturado no peridomicílio no cerrado. No ambiente natural esta espécie ocupa buracos de árvores e bromélias. Triatoma pseudomaculata é o segundo triatomíneo mais coletado no intradomicílio em quase todos os estados do semiárido brasileiro (Costa et al. 2003, Sarquis et al. 2004). No ambiente natural, T. pseudomaculata ocorre principalmente sob cascas e no oco de árvores, como a jurema (Mimosa tenuiflora) (Freitas et al. 2004).

Entre os ecótopos ocupados pelos triatomíneos, os domiciliares e peridomiciliares são os principais envolvidos na ecoepidemiologia da doença de Chagas. Como mencionado no capítulo 2 , somente uma fração muito pequena das espécies descritas pode ser incriminada pela manutenção da endemia chagásica. A associação do triatomíneo com o ser humano (processo de domiciliação ou sinantrópico) dentro de um contexto ecoepidemiológico será tratada no tópico seguinte.

\section{O processo de domiciliação dos triatomíneos}

Pessoa (1962) comentou a importância do processo sinantrópico dos triatomíneos, explicando como sendo uma associação do vetor com o ecótopo construído ou modificado pelo ser humano. Em sua obra, o autor ressalta a íntima correlação entre a domiciliação dos triatomíneos e a transmissão da doença de Chagas, que é então favorecida pela coabitação do vetor e do ser humano.

Schofield et al. (1999) mencionaram que, embora tenham sido desenvolvidas explicações razoáveis para a compreensão do processo de domiciliação dos triatomíneos, as pesquisas ainda apresentam-se distantes da elucidação dos mecanismos que produziram este evento, o que seria um dos maiores desafios para a próxima década. Dez anos após, no centenário da descoberta da doença de Chagas, pouco se avançou para elucidar o mecanismo envolvido neste processo e paradoxalmente, a literatura apresentou uma série de episódios indicando que espécies de triatomíneos, até então restritas ao ambiente silvestre, vinham colonizando ou sendo frequentemente encontradas no ambiente domiciliar (Almeida et al. 2000, Reyes-Lugo \& Rodriguez-Acosta 2000, Costa et al. 2003, Santos et al. 2005, Almeida et al. 2009).

As opiniões sobre os processos envolvidos na domiciliação dos vetores da doença de Chagas são divergentes. Alguns autores (Aragão 1983) consideram tratar-se de simples oportunismo frente a escassez das fontes naturais de alimento e outros acreditam tratar-se de processo gradual de 
adaptação, sujeito à seleção natural (Forattini 1980, Pessoa 1962). Como a maioria das espécies de triatomíneos reconhecidos como domiciliados (T. infestans, T. brasiliensis, R. prolixus e P. megistus) apresentam-se distintas quanto ao ramo filogenético (veja capítulos 3 e 13), origem ecotípica primária e ecossistema (vide tópicos anteriores), é mais provável que o processo de domiciliação de cada espécie apresente um modelo próprio com diferenças também marcantes (Dujardin et al. 2009).

O "modelo Triatoma infestans" oferece importantes indícios sobre o possível processo de adaptação de um vetor ao ambiente domiciliar. Ressalta-se porém a necessidade de cautela no uso do termo "adaptação". Na biologia evolutiva, o termo descreve o processo pelo qual uma característica, devido ao aumento que confere no valor adaptativo, foi moldada por forças específicas de seleção natural fixando a variação genética (Futuyma 1995). Segundo Ávila-Pires (1995) o termo "adaptação" tem sido frequentemente empregado sem argumentos consistentes. Segundo esse autor, a adaptação de um organismo envolve modificação genética na qual a aquisição de novos padrões de comportamento e modificações da biologia, por exemplo são observados. Tanto Schofield et al. (1999) quanto Ávila-Pires (1995) admitem que esse processo envolve simplificação genética, com perda de genes, como aqueles responsáveis pela capacidade de retornar ao ecótopo silvestre.

No caso de T. infestans, o termo "adaptação" parece ser adequado, pois estudos recentes sugeriram que as populações de $T$. infestans em áreas onde ela também ocorre no ambiente silvestre (Andes Bolivianos) são distintas genotipicamente das populações domiciliares (Richer et al. 2007). Além disso, embora no passado T. infestans tenha apresentado altos índices de infestação domiciliar na maioria dos estados brasileiros, esta espécie não foi capaz de colonizar o ambiente silvestre. Ou seja, tanto a diferenciação observada por Richer et al. (2007) para populações domiciliadas, quanto a sugestão de que estas não são capazes de colonizar o ambiente silvestre em nenhum dos ecossistemas onde ela infestou domicílios, sugere que as populações domiciliadas desta espécie realmente possam ter perdido os genes associados à sua habilidade para colonizar ambientes naturais.

Desde 1980, Forattini já havia elaborado hipóteses para explicar o processo de domiciliação dos triatomíneos, baseado no modelo T. infestans, mencionando que:

[...] a partir do desenvolvimento da domiciliação e do progredir das alterações do meio, instala-se o isolamento domiciliar que tenderá cada vez mais à diferenciação desse comportamento. Compreende-se assim a possibilidade de evolução no sentido de populações acentuada ou mesmo estritamente sinantrópicas [...]

Forattini (1980) levantou ainda uma série de discussões sobre a origem do fenômeno da domiciliação para este vetor. Baseado em informações biogeográficas, esse autor mencionou que o processo de domiciliação de $T$. infestans já havia sido consolidado no período pré-colombiano. Através da autópsia de múmias, Rothhammer et al. (1985) apresentaram outras evidências de que a adaptação de $T$. infestans ao domicílio tenha favorecido sua dispersão para outras áreas durante o período pré-colombiano, seguindo as migrações tribais pré-incas da Bolívia ao sul do Peru e norte do Chile. Segundo Silveira \& Vinhaes (1999) e Dias et al. (2000, 2002), no início de 1900, possivelmente $T$. infestans, já adaptado ao domicílio, seguiu o circuito de importação e exportação do café, passando pelo Paraguai e Argentina até chegar a São Paulo. Posteriormente, T. infestans seguiu duas rotas 
independentes de ocupação e desmatamento de florestas litorâneas, colonizando o sul e nordeste brasileiros. Sua ocupação nestas regiões causou o maior número de casos de infecção pela doença de Chagas já registrado na história desta moléstia no Brasil.

O modelo de adaptação às habitações humanas por T. infestans foi proposto por Schofield et al. (1999) e aqui modificado, estando representado na Figura 11.6. Postula-se que a população silvestre (1) mantém-se em panmixia (cruzamento aleatório) e com destacada variabilidade genética. $O$ evento primário associado ao processo de domiciliação trata-se de um fragmento (pequeno número de espécimes representantes) dessa população que invade o peridomicílio (2) ou diretamente o domicílio (3). Devido a características pré-adaptativas (descritas a seguir), esta população invasora se expande mantendo-se relativamente homogênea geneticamente por efeito fundador. No peridomicilio ou no domicilio o genótipo é moldado (4), ou seja, ocorre a modificação genética envolvendo a adaptação stricto senso ao ambiente domiciliar por seleção natural em função do ecótopo domiciliar. Assim, a espécie "apura" a carga genética responsável pela adaptação ao domicílio (como os genes associados ao condicionamento biológico a este novo ambiente), mas também perde uma série de outros associados à sua capacidade para retornar ao ambiente silvestre, bem como grande parte da variabilidade genética. Por essa razão, as setas após o evento 4, são unidirecionais. Esse evento (4-5) pode se repetir por vários episódios até que uma população bem adaptada ao domicílio será aquela capaz de invadir domicílios adjacentes (6) por dispersão passiva ou ativa em diferentes regiões biogeográficas. Para os triatomíneos, ressalta-se que tal fluxograma (Figura 11.6) representa uma hipótese e que muitos estudos ainda são necessários.

O ambiente intradomiciliar apresenta-se relativamente homogêneo, mesmo quando localizados em diferentes ecossistemas, pois as condições no intradomicílio minimizam a variação dos fatores abióticos (como a temperatura e umidade). Esse ambiente ainda fornece normalmente uma fonte constante de recursos alimentares (o ser humano e animais domesticados). Assim, os triatomíneos adaptados ao ambiente domiciliar podem se dispersar para domicílios inseridos nos diferentes ecossistemas, como aconteceu com $T$. infestans. Um paralelo referente ao processo observado para T. infestans pode ser traçado para um dos insetos mais sinantrópicos conhecidos: a mosca que leva

3 Fenômeno observado quando um subgrupo proveniente de uma população maior se estabelece como entidade isolada. O pool gênico (expectativa da diversidade total) desta nova população transporta só uma fração da diversidade genética da população original. 
o domicílio em seu nome científico (Musca domestica). Segundo Povolny (1971), esse inseto, hoje cosmopolita, evoluiu de uma linhagem silvestre coprófaga, associada a animais ruminantes do velho mundo, possivelmente na região oeste paleártica. A domesticação de ruminantes foi um possível evento que atuou possibilitando condições para que a mosca se aproximasse do ser humano e evoluísse até ao nível atual de sinantropia. Após a adaptação aos domicílios, a dispersão para esta espécie foi tão destacada, que a origem precisa da linhagem original é incerta (Marquez \& Krafsur 2002) e a mosca doméstica não colonizou quaisquer dos ecossistemas naturais para aonde ela se dispersou. Assim sendo, o ambiente alterado pelo ser humano, o que inclui a introdução de animais domesticados (como os ruminantes, no caso da mosca doméstica), parece ter tido forte influência na evolução e adaptação de algumas espécies (ou linhagens) altamente sinantrópicas hoje conhecidas. De modo semelhante, sugere-se para T. infestans, que a domesticação de preás (Cavia spp.) nos vales andinos exerceu papel importante na domiciliação desse vetor (Usinger et al. 1966).

Silveira \& Rezende (1984) classificaram T. infestans e T. rubrofasciata como espécies introduzidas e que tiveram sua dispersão favorecida pela interação entre o evento da domiciliação e atividades humanas. Aquela última espécie foi considerada de distribuição pantropical, tendo sido postulado que populações provenientes do Velho Mundo alcançaram o Novo Mundo durante o século XVII-XX através de embarcações (Gorla et al. 1997, Patterson et al. 2001, Hypsa et al. 2002). Entretanto, sua preferência ecotípica por buracos de roedores reduz seu potencial de transmissão da doença de Chagas (Brasil, 1986).

Segundo revisão realizada por Schofield et al. (1999), o processo de domiciliação em triatomíneos pode ser encarado como uma extensão da rota evolutiva de predador para sugador em ninhos-abrigo, no qual o habitat domiciliar representa simplesmente um novo tipo de abrigo de vertebrado. Segundo Bock (1959), características pré-adaptativas são aquelas que não evoluíram em antecipação a uma futura, mas que atuam positivamente para a consolidação de um novo caráter. As características microclimáticas dos habitats de $T$. brasiliensis foram observadas em ecótopos silvestres, domiciliares e peridomiciliares no estado de Ceará, Brasil. Foi evidenciado que para esta espécie os parâmetros ambientais representam fatores determinantes na escolha do microambiente, podendo o inseto estar limitado a locais quentes e secos, de baixa amplitude. Assim, as fendas nas paredes no interior de casas no semiárido nordestino representam um ambiente adequado para $T$. brasiliensis, devido à similaridade com os parâmetros climáticos dos refúgios nos pedregais silvestres (Lorenzo et al. 2000). Portanto, populações silvestres dessa espécie parecem possuir características pré-adaptativas ao ecótopo domiciliar.

Após a eliminação de $T$. infestans no Brasil, várias outras espécies vem invadindo e colonizando o domicílio em áreas previamente ocupadas por esse vetor (veja capítulo 2), demonstrando muitas vezes fortes evidências de substituição de nicho ecológico ${ }^{4}$ (Almeida et al. 2000). Segundo Silveira \& Rezende (1984), T. rubrovaria e $R$. neglectus, ambas encontradas naturalmente infectadas por T. cruzi, agrupam-se entre as espécies que vêm ocupando nichos deixados vagos pela eliminação de T. infestans, respectivamente, no Rio Grande do Sul (RS) e em algumas áreas do estado de Goiás. Rhodnius nasutus foi classificada como espécie que apresenta risco de transmissão de $T$. cruzi devido à constatação da existência de colônias intradomiciliares

$4 \quad$ O nicho ecológico refere-se ao conjunto de atividades (ou o papel) que a espécie desempenha no ecótopo, ou ecossistema. Estas atividades incluem as relações alimentares, obtenção de abrigos e locais de reprodução, entre outras. 
nos estados do Ceará. Essa sugestão foi posteriormente reafirmada por Sarquis et al. (2006).

Para o modelo $T$. brasiliensis, atualmente o mais importante vetor da doença de Chagas no semiárido brasileiro, as características pré-adaptativas destacadas por Lorenzo et al. (2000) fazem com que esta espécie represente de um desafio operacional, porque esse vetor mantém alta pressão de invasão domiciliar e sua eliminação nesse ambiente não evita a constante recolonização a partir de focos silvestres (Silveira \& Vinhaes 1999, Costa et al. 2003).

Como mencionado no início desse tópico, entender detalhadamente o mecanismo responsável pela domiciliação dos triatomíneos é ainda de um desafio importante e com possível aplicabilidade no combate à endemia chagásica. Como a adaptação está associada com o campo da genética e a ciência está neste momento muito próxima do sequenciamento do genoma de $R$. prolixus, espera-se que futuramente informações mais consistentes possam auxiliar a desvendar o fenômeno da domiciliação nos triatomíneos.

\section{O uso adequado de termos e conceitos}

Já em 1982, Margolis et al. chamaram a atenção para o uso impreciso de termos e conceitos ecológicos em parasitologia, talvez como resultado da carência de ecólogos atuando na área, se comparada com a destacada atuação de especialistas em epidemiologia, biologia molecular, medicina diagnóstica e clínica, entre outras. Posteriormente, Ávila-Pires (1995) lançou uma obra, cujo título traduzido é "O uso impróprio de alguns termos ecológicos e conceitos em epidemiologia", na qual esse autor contextualiza a problemática com enfoque na Ecologia dos vetores da doença de Chagas. Foram selecionados aqui alguns termos e conceitos enfatizados pelos autores acima citados, e outros que foram considerados importantes.

Várias são as relações ecológicas envolvidas na epidemiologia da doença de Chagas. Como a ecologia aborda a relação dos seres vivos entre eles, e desses com o meio, torna-se interessante, primeiramente, abordar o tipo de relação observada entre o triatomíneo e o ser humano, pois a relação de parasitismo (T. cruzi vs. ser humano/inseto/reservatório) já foi comentada no capítulo 7.

Diversas evidências sugerem que os triatomíneos tenham surgido a partir de linhagens de insetos predadores que habitavam "ninhos" de vertebrados, onde estes insetos desenvolveram a hematofagia (Schofield et al. 1999) e, de fato, a maioria dos demais representantes da família dos triatomíneos (Reduviidae) são predadores obrigatórios. Na relação de predação (não só para os reduvídeos), os predadores são geralmente maiores que sua presa, que morre antes ou durante o repasto do predador. Em geral, os reduvídeos (excluindo-se os triatomíneos) possuem as pernas dianteiras adaptadas para agarrar firmemente a presa e geralmente possuem um componente salivar que auxilia na paralisação e abate da presa. Se eventualmente essa substância é injetada em vertebrados, frequentemente é acompanhada por episódios de dor, com variáveis manifestações alérgicas e inflamatórias. Os triatomíneos, por outro lado, possuem uma substância anticoagulante, vasodilatadora e indolor na saliva. Uma vez que os barbeiros não matam o hospedeiro durante o repasto sanguíneo e que a fonte alimentar é muito maior que o triatomíneo, a relação deste com a sua fonte alimentar não se encaixa no conceito de predação.

Muitos artrópodes, como os piolhos, são considerados parasitas (mais especificamente, ecto- 
parasitas). Assim como os triatomíneos, esses insetos são hematófagos obrigatórios. Entretanto, no ectoparasitismo os parasitas permanecem toda ou boa parte da vida sobre o hospedeiro e apresentam geralmente elevado grau de especificidade parasita/hospedeiro. Porém, ao contrário dos ectoparasitas, os triatomíneos não permanecem sobre o hospedeiro e apresentam um considerável grau de ecletismo alimentar. Na generalidade dos casos, os triatomíneos se alimentam sobre várias espécies de vertebrados (especialmente homeotérmicos) que porventura possam estar próximos a eles. A alimentação ocorre especialmente durante o sono do hospedeiro.

Desta forma, qual seria a denominação mais adequada para a relação ecológica observada entre os triatomíneos e sua fonte alimentar? Dada a incompatibilidade da terminologia "predação" e "ectoparasitismo", Brusca \& Brusca (1990) sugerem o uso do termo micropredação para a relação dos triatomíneos com o ser humano (ou com suas demais fontes alimentares).

Muitos autores utilizam o termo "antropofilia" para os triatomíneos que se alimentam em humanos, classificando uma ou outra espécie como antropofílica, ou não antropofílica. Esse termo implica em uma preferência por alimentar-se sobre humanos. Entretanto, vários estudos, bem como observações em laboratório demonstram que os triatomíneos podem se alimentar sobre uma gama ampla de vertebrados e, uma vez com fome, raramente rejeitam animais homeotérmicos. Portanto, como destacado por Ávila-Pires (1995), a fonte alimentar utilizada pelos triatomíneos no ato da micropredação é um resultado de mero oportunismo. Conforme mencionado anteriormente, os triatomíneos apresentam especificidade ecotípica (Gaunt \& Miles 2000), e portanto, sua dieta é condicionada aos animais que habitam este mesmo ecótopo. Ressalta-se que os triatomíneos não podem se sujeitar à escolha entre uma gama muito ampla de fontes alimentares, como acontece com os mosquitos. O termo antropofilia (bem como outros, tais como: a zoofilia, a ornitofilia, etc.) deve então ser utilizado para outros micropredadores, como os mosquitos, os flebotomíneos, os simulídeos, etc., que apresentam destacada mobilidade ligada à escolha da fonte alimentar. Nesse contexto, a utilização do termo "preferência alimentar" também deve ser utilizada com cautela e talvez seja mais adequado substituí-la por "fontes alimentares naturais".

Ávila-Pires (1995) sugere que se deve também evitar o uso do termo "dispersão" para a simples invasão ou colonização domiciliar. Esse autor enfatiza que a "dispersão" tem origem na biogeografia e também é frequentemente utilizado na genética de populações para a compreensão do fluxo gênico.

Entre os termos utilizados na eco-epidemiologia da doença de chagas, a caracterização ambiental é frequente alvo de dúvidas e emprego ambíguo. O termo "ambiente silvestre' tem sido muito empregado para qualquer ambiente além dos limites domiciliares e peridomiciliares em áreas rurais. Já em 1938, Lund utilizou o termo "ruderal" que foi posteriormente redefinido por Warming \& Vahl (1909) como sendo um ambiente com a flora original alterada, onde componentes da vegetação foram substituídos por uma vegetação relativamente recente, muitas vezes com espécies exóticas com fins agrícolas ou propícias a atividades pastoris. Esses componentes vegetais tem vida curta, pois sofrem colheita ou são fonte alimentar do gado caprino, ovino ou bovino. Nesse ambiente muitos dos integrantes vertebrados da fauna silvestre foram caçados ou simplesmente eliminados pelos criadores de animais e uma outra parte deixou naturalmente o ambiente, devido à escassez de sua fonte alimentar natural (vegetação ou presa). Sem dúvidas, a entomofauna também foi 
alterada nesse novo ambiente. A importância da caracterização precisa do ambiente onde os triatomíneos ocorrem foi enfatizada por Ávila-Pires (1995) e posteriormente por Almeida et al. (2002). Almeida et al. (2008) mencionaram que as populações de triatomíneos que ocorrem no ambiente ruderal podem estar sendo favorecidas pelas alterações ambientais, que podem excluir parte de seus predadores, mas a disponibilidade de fontes alimentares foi incrementada com a presença dos animais domesticados. Triatoma brasiliensis, por exemplo, parece não sofrer com as alterações ambientais, ao contrário, alguns estudos indicam que estas possam favorecer a espécie (Almeida et al. 2008, Sarquis et al. 2010). Para esses autores, embora os triatomíneos não apresentem em melhor condição nutricional (avaliada pelo peso corporal) do que aqueles encontrados em ambientes domiciliares ou peridomiciliares, as colônias ruderais conseguem manter relativa abundância e densidade durante todo o ano. Forattini et al. $(1971 a, b)$ também enfatizaram que o ambiente alterado possivelmente favoreça a ocorrência e manutenção de algumas espécies, como T. sordida. Entretanto, a maioria dos autores continua empregando o termo "silvestre" de forma inconsistente, sem uma observação detalhada dos componentes da fauna e flora locais. Lacher (1981) alerta para a necessidade da observação paisagística em estudos na Caatinga, enfatizando que muitas vezes é complexa a diferenciação do ambiente alterado para o não alterado. Tal observação não é facilitada pelas características ambientais naturais da Caatinga, com vegetação arbustiva baixa e clareiras naturais.

O ambiente ruderal difere do ambiente silvestre stricto senso principalmente porque neste último ocorre uma grande variedade de animais silvestres. Ressalta-se que alguns animais reconhecidos como tais por alguns autores, como o gambá (Didelphis spp.), tratam-se na verdade de animais sinantrópicos e importantes reservatórios naturais de T. cruzi (Ruiz-Piña \& Cruz-Reyes 2002).

\section{Fauna associada}

A coabitação e utilização de hemolinfa de barata (Blaptica dubia) como fonte alimentar de triatomíneos que ocorrem em pedregais no Rio Grande do Sul (T. rubrovaria e T. circummaculata) foi demonstrada por Lorosa et al. (2000) em laboratório. Em seguida, Almeida et al. (2002, 2009b) mencionam que uma terceira espécie de triatomíneo pode ocupar esse mesmo ambiente ( $T$. carcavalloi), junto com esta mesma espécie de barata. A estreita afinidade filogenética entre os triatomíneos acima citados (Almeida et al. 2009b) pode indicar que T. carcavalloi também se alimente desta barata.

Sob o ponto de vista eco-epidemiológico, a fauna de vertebrados (especialmente mamíferos, veja capítulo 7) que coabita com os triatomíneos e os predadores apresentam interesse particular. Salvatella \& Rodrigues (1983) sugeriram que um reduvídeo (Zelurus femoralis) possa atuar como predador natural de triatomíneos no Rio Grande do Sul. De acordo com Costa Lima (1928), Pellegrino (1950), Rabinovich (1970) e Fernandes et al. (1990) os triatomíneos podem apresentar seus ovos atacados por um himenóptero (Telenomus fariai) no habitat natural (P. megistus, T. infestans e M. phyllosomus) e sob condições de laboratório (P. megistus e T. viticeps). Ninfas e adultos de T. brasiliensis (e possivelmente de outras espécies de triatomíneos) podem apresentar Megaselia scalaris (Diptera, Phoridae) como parasitoide (Costa et al. 2007). 
Almeida et al. (2009a) listaram 20 morfoespécies de aracnídeos como possíveis predadores de triatomíneos em Gentio do Ouro, Bahia, destacando que aranhas do gênero Isoctenus (Ctenidae) podem atuar no controle natural de populações domiciliares de $T$. sherlocki, por se tratarem de aranhas frequentes neste ambiente em comunidades de garimpo.

Contudo, nenhum estudo em campo demonstrou eficiência para utilizar outros artrópodes como controladores naturais de triatomíneos. O uso de microrganismos em campo também ainda não apresentou resultados aplicáveis, entretanto, como enfatizado por Beard et al. (2002), o campo de estudo representa linha de pesquisa promissora.

\section{Indicadores entomológicos}

Para a compreensão do uso dos indicadores entomológicos por técnicos da vigilância sanitária e por pesquisadores, torna-se necessária uma sucinta explicação de como o trabalho de campo e a compilação dos dados são realizados de uma forma coordenada entre os centros de vigilância sanitária e as instituições de pesquisa. O trabalho integrado e tem sido responsável pelo sucesso no controle dos vetores da doença de Chagas no Brasil.

\section{Trabalho em campo por agentes da Vigilância Sanitária.}

De acordo com o Guia para a vigilância epidemiológica da doença de Chagas/Ministério da Saúde, seguindo sugestões da Organização Panamericana de Saúde (OPAS, 2003) a pesquisa entomológica por agentes de saúde é realizada por pessoal treinado e desenvolvida exclusivamente nas unidades domiciliares (UD). As UDs compreendem o intradomicílio e o peridomicílio, com seus anexos. Os anexos, tais como galinheiros, chiqueiros, currais e galpões são possíveis locais de abrigo para os vetores. Desta forma, todo o entorno extradomiciliar próximo é investigado, visando a verificação de possíveis situações propícias para a transmissão vetorial.

Os agentes da vigilância sanitária ainda são treinados para colher informações junto à população ou junto a outros agentes de controle de outras doenças (como a leishmaniose e a malária) que fazem rotineiramente a visita domiciliar. Nos postos de identificação triatomínica, os vigilantes são orientados a criar mostruários com as espécies que ocorrem na região tanto para o treinamento do pessoal envolvido nas pesquisas, como para inquéritos entomológicos com a população local. Desta forma, a equipe é capacitada para o reconhecimento das diferentes espécies de vetores que ocorrem na região, bem como por outras que porventura possam ampliar sua área de ocorrência.

Nos postos de vigilância sanitária, os agentes de saúde ainda mantém um detalhado banco de informação sobre toda a área de abrangência da sua unidade, apresentado as localidades e número de moradores (entre outras informações). No banco de dados ainda são armazenados detalhes das investigações, como por exemplo o número e a identificação das casas positivas para triatomíneos, a espécie (e o número de espécimes) capturada(s), as borrifações domiciliares com inseticidas, etc. Estas informações são posteriormente enviadas à coordenação estadual. Este trabalho ainda abrange o monitoramento do processo de ocupação humana da região, como a identificação de novos assentamentos. Este banco de dados visa principalmente organizar e direcionar as borrifações periódicas das UDs com inseticidas piretroides. Ressalta-se que este trabalho, desenvolvido 
e aperfeiçoado de forma criteriosa ao longo dos anos, foi elemento fundamental no controle de $T$. infestans em quase todo o Brasil e pela manutenção dos baixos índices de colonização domiciliar por vetores secundários (Dias et al. 2000).

\section{Equações aplicadas na vigilância entomológica}

Para determinar se um achado em campo, como triatomíneos no domicílio, representa um risco real de transmissão, manutenção ou emergência da doença de Chagas, foram desenvolvidos indicadores entomológicos, que nada mais são do que equações baseadas em ecologia e ecoepidemiologia. Os indicadores entomológicos foram divulgados pela Organização Pan-americana de Saúde em 1993 e revisados em 2003 (OPAS 2003). Desde então, tanto os órgãos de vigilância epidemiológica, quanto os pesquisadores vem utilizando modelos uniformizados que permitem o planejamento das medidas de controle e padronização da informação científica obtida em campo.

Os indicadores entomológicos mais aplicados na pesquisa triatomínica são o índice de infestação domiciliar (= número de unidades domiciliares com presença de triatomíneos $x$ 100, dividido pelo número de unidades domiciliares pesquisadas); a densidade triatomínica domiciliar (número de exemplares de triatomíneos capturados dividido pelo número de unidades domiciliares pesquisadas); o índice de infecção natural por T. cruzi (discutido no capítulo 7) e o índice de colonização (= número de unidades domiciliares com presença de ninfas $\times 100$, dividido pelo número de unidades domiciliares pesquisadas). Ressalta-se que este último tem especial interesse na ecoepidemiologia da doença de Chagas, porque o encontro unicamente de adultos pode significar mera invasão domiciliar. Somente o encontro de insetos em vários estádios de desenvolvimento pode realmente ser utilizado como indicador de colonização, conforme já enfatizado no tópico "Ecótopos dos vetores da doença de Chagas".

Esses indicadores possibilitaram que alguns autores (ex: Silveira \& Rezende 1984, Costa et al. 2003, Almeida et al. 2000, 2008, 2009) desenvolvessem classificações para os triatomíneos, com base em seu status de sinantropização no Brasil. Entre os exemplos dessas classificações (frequentemente alvo de controvérsias), podemos citar os triatomíneos tidos como: 1- espécies exóticas no Brasil e estritamente domiciliadas (ex: T. infestans e T. rubrofasciata), 2- triatomíneos autóctones, mas que colonizam continuamente o domicílio (ex: T. brasiliensis e T. pseudomaculata), 3- triatomíneos autóctones, mas que invadem o domicílio esporadicamente, formando colônias domiciliares pouco numerosas (ex: $R$. nasutus), 4- triatomíneos autóctones em processo de domiciliação (ex: T. sherlocki), 5- triatomíneos autóctones que invadem continuamente o domicílio, mas raramente formam colônias intradomiciliares (ex: T. rubrovaria e T. circummaculata) e 5- triatomíneos estritamente silvestres (ex: T. petrocchiae).

\section{Trabalho de campo voltado para a pesquisa científica}

Em seu trabalho de campo, o pesquisador pode lançar mão de várias técnicas de coleta. No intra e peridomicílio o pesquisador pode contar com o apoio dos técnicos das secretarias de vigilância em saúde, que foram treinados para a captura manual com o auxílio de pinças e/ou desalojantes químicos que são baseados em baixas concentrações de inseticidas (veja capítulo 10). 
Uma armadilha desenvolvida por Noireau et al. (2002) vem sendo largamente utilizada em pesquisas triatomínicas, principalmente no ambiente silvestre. Tal armadilha consiste de recipiente plástico pequeno (250 ou $500 \mathrm{~cm}^{3}$ ) coberto no topo com uma tela e na parte lateral externa apresenta uma fita adesiva dupla face. No interior da armadilha, um camundongo ou pinto (Lima \& Sarquis 2007) é utilizado como isca. Esse apa-

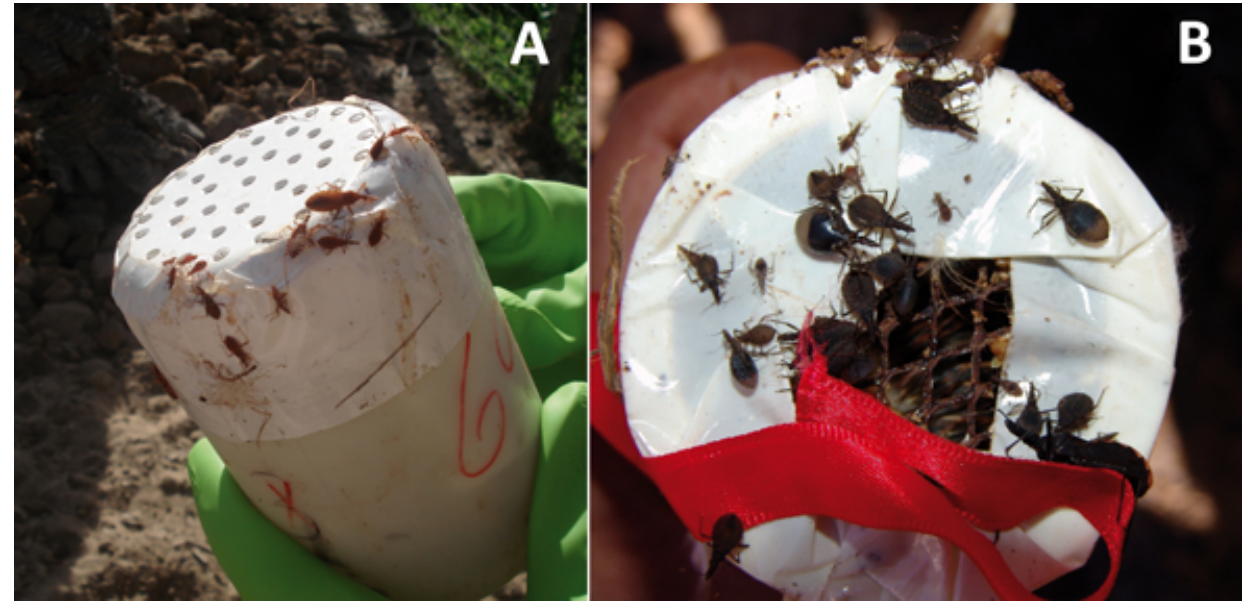

Figura 11.7: Armadilha proposta por Noireau et al. (2002), com (A) exemplares de $R$. nasutus coletados do Ceará e (B) T. costalimai em Tocantins.

rato foi projetado inicialmente para coletar triatomíneos em ocos de árvores no Chaco boliviano, mas provou ser eficaz para amostrar triatomíneos em vários outros ecossistemas (ex: Caatinga, Bacia Amazônica, e Mata Atlântica) e ecótopos (ex: árvores robustas, palmeiras e pedregais). Tais armadilhas são geralmente colocadas no entardecer e inspecionadas na manhã seguinte, permanecendo por não mais do que $14 \mathrm{~h}$, para evitar a exaustão da isca/camundongo (mantido com reserva nutricional). Os triatomíneos que buscam a isca podem ficar aderidos à cola da fita adesiva e são capturados pelo pesquisador (Figura 11.7).

As armadilhas luminosas constituem de um pano branco estendido verticalmente próximo a uma fonte de luz artificial, que é eficaz para a captura de várias espécies no período noturno. Os triatomíneos atraídos pela fonte luminosa chegam através do voo, sendo estes capturados manualmente com o auxílio de pinças (Figura 11.8). Carbajal de la Fuente et al. (2007) comprovou a eficiência dessa armadilha para a coleta de $T$. juazeirensis e T. pseudomaculata.

A realização de coletas manuais também trazem relevantes resultados para os trabalhos de campo. Nos ecótopos onde os triatomíneos ocorrem em pedras, recomenda-se que sejam efetuadas coletas noturnas (Figura 11.9), quando
Figura 11.8: Armadilha luminosa que obteve sucesso na coleta de T. juazeirensis e T. pesudomaculata na Bahia.

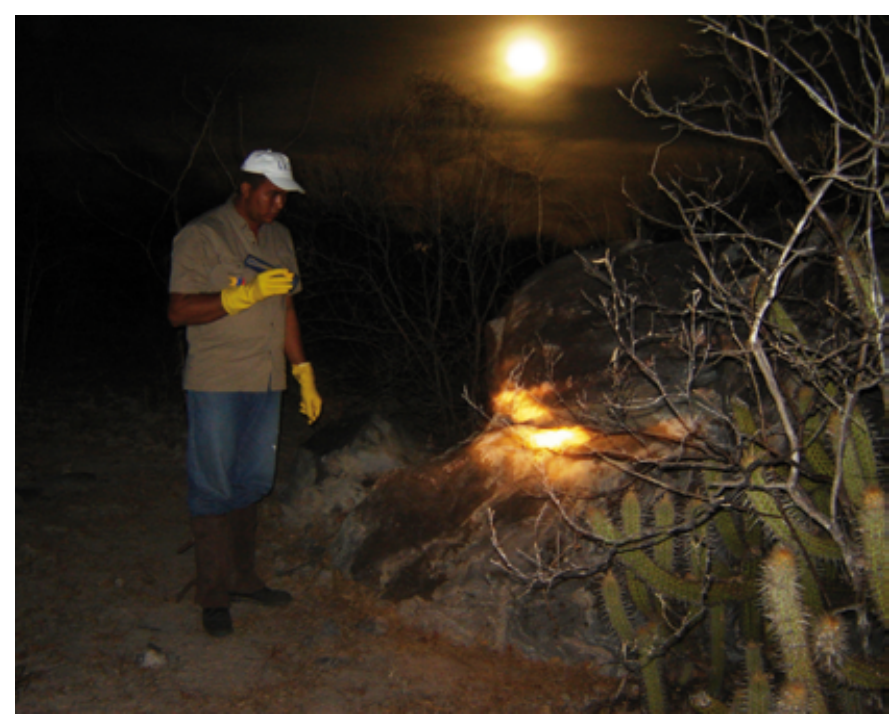

Figura 11.9: Captura manual (com auxílio de pinças) noturna no Ceará.

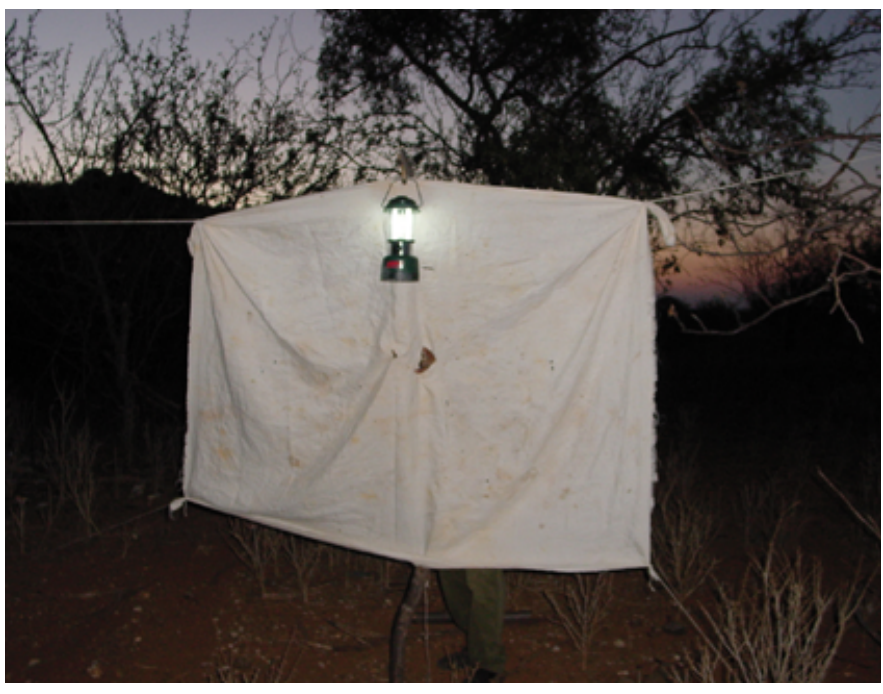


os insetos saem para procurar alimento, copular ou simplesmente se dispersar, tendo sido amplamente utilizada (ex: Almeida et al. 2002, Costa et al. 1998, Almeida et al. 2009, Sarquis et al. 2010). A utilização da armadilha proposta por Noireau et al. (2002), colocada nas copas das palmeiras com o auxílio de uma haste (Figura 11.10) poupa a árvore do corte (Lima \& Sarquis 2009). A pesquisa triatomínica também obtém bons resultados com a coleta manual em ninhos de aves ou matéria orgânica presente nas palmeiras.

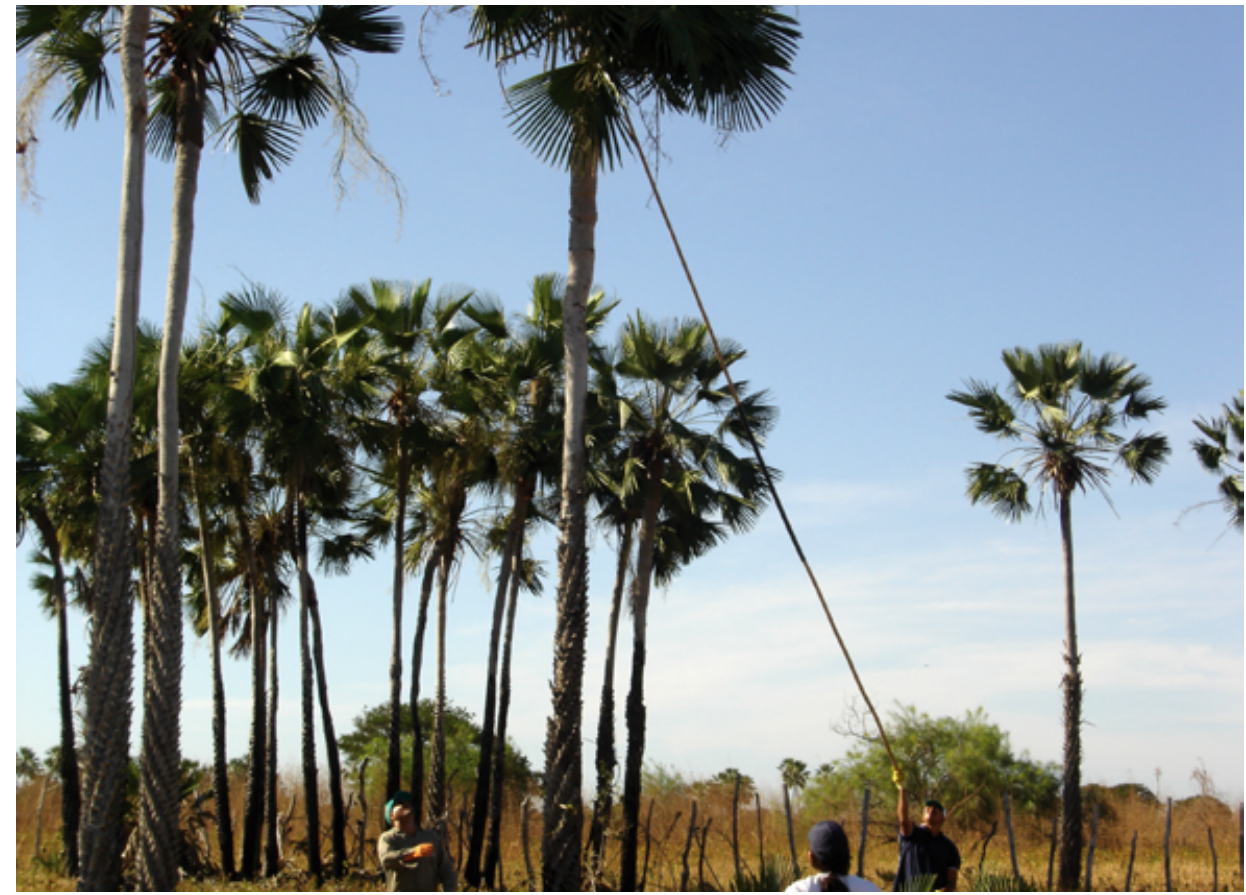

Figura 11.10: Colocação da armadilha tipo Noireau et al. (2002) na copa de uma palmeira por meio de uma haste, Ceará.

\section{Aspectos ecoepidemiológicos dos vetores}

Uma das dificuldades para a compreensão da ecoepidemiologia da doença de Chagas é a complexa interação dos múltiplos componentes do cenário da transmissão: as interações entre o vetor, reservatório, parasita, ser humano e ambiente numa escala espaço-temporal. Existem muitas espécies de vetores (veja capítulo 3), hospedeiros vertebrados e linhagens do parasita envolvidos (veja capítulo 7) neste sistema e, adicionalmente, outros elementos como a vegetação, predadores, topografia, geologia e clima apresentam também influência (Moore 2008).

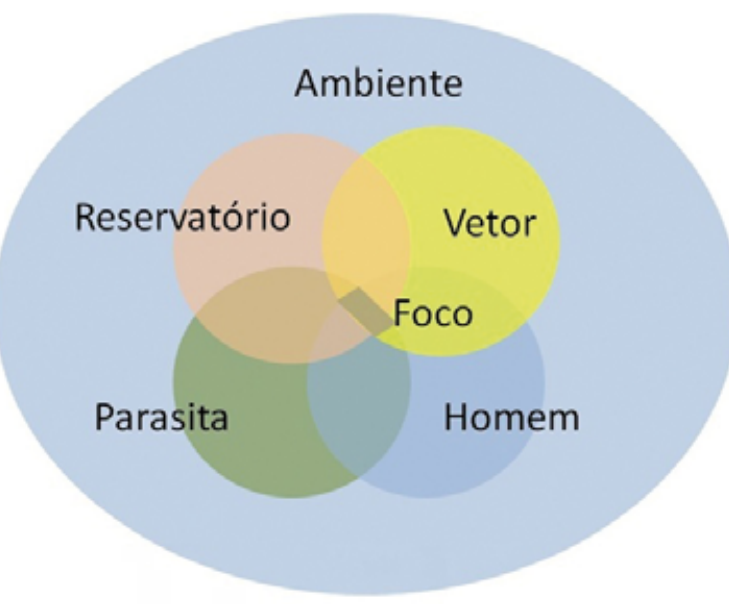

Figura 11.11: Conceito de foco ou nidus de transmissão parasitária, mostrando como o vetor, reservatório, parasita e ser humano interagem em um ambiente propício.
O clima varia a uma escala espacial e temporal, o que pode ser dividido em sazonal (intranual) e anual (interanual). Acredita-se que as alterações climáticas vem influenciando fortemente nos padrões epidemiológicos de transmissão chagásica. Para que a transmissão silvestre ocorra, as variáveis climáticas devem estar dentro dos padrões de tolerância das espécies vetoras e reservatórios e adequadas para a replicação do patógeno. Se dentro do ecossistema propício, estiverem presentes o inseto vetor (veja capítulo 8), o reservatório (veja capítulo 7), o parasita (veja capítulo 7) e o ser humano, o foco ou nidus de transmissão pode ser estabelecido (Figura 11.11). Ressalta-se que o ser humano também pode ser considerado reservatório de $T$. cruzi em muitos casos (Dias 2006). 
Como as variáveis ambientais tem influência direta sobre a distribuição dos vetores, informações provenientes de diferentes campos da ciência (ex: cobertura vegetal, temperatura, pluviometria) são de suma importância e podem ser estimadas a partir de dados obtidos por sensores remotos situados em satélites espaciais. Para a doença de Chagas, o sistema de informação geográfica (SIG), tem oferecido relevantes contribuições utilizando esses sensores, visando antecipar e atualizar a distribuição geográfica de triatomíneos silvestres e domiciliados (Almeida et al. 2009). A modelagem de nicho ecológico (MNE) ainda é capaz de realizar uma análise comparativa entre diferentes cenários de transmissão e proporcionar informações sobre a possível dispersão de um vetor para novas áreas (Costa et al. 2002, Abad-Franch et al. 2010).

Como enfatizado por Moore (2008), embora as novas ferramentas baseadas no sensoriamento remoto (ex: SIG e MNE) promovam uma integração de diferentes disciplinas, a colaboração interdisciplinar é fundamental na Ecologia dos vetores da doença de Chagas. Este autor recomenda a formação de redes com especialistas em diferentes áreas da ciência para cada grupo vetorial, seguida da sumarização de seus achados em uma linguagem simples, voltada para a contribuição e resolução de determinada questão ecoepidemiológica. 